\title{
Application of the Arduino Platform for Recording Wind Waves
}

\author{
V. E. Smolov, A. F. Rozvadovskiy* \\ Marine Hydrophysical Institute of RAS, Sevastopol, Russia \\ *rozvadovsky@yandex.ru
}

\begin{abstract}
Purpose. The paper describes development of a device (placed on the Arduino platform) for recording wind waves. It is intended for the wave gauge of Marine Hydrophysical Institute, RAS, which is installed and applied at the oceanographic platform in Katsiveli. The device is designed to record and store the wave gauge data in an off-line mode. At that, it is protected from power surges and environmental effects (dust, moisture, temperature drops).

Methods and Results. Two versions of the Arduino-placed recording device are represented: for the single- and six-string wave gauges. Their hardware and software are described; block diagram of the applied software algorithms and electrical connection schemes are given. Particular attention is paid to stable functioning of the devices, namely continuity of the data reading, recording and storing, as well as synchronization of the obtained measurement results with the time of record. The example of the sea level elevations recorded in course of a year is cited.

Conclusions. Development, construction and testing of the Arduino-placed device for recording wind waves are described in the paper. Since 2015, the off-line operation of the device has shown high efficiency, reliability and stability; at that, the risks of losing the measurement results are minimal.
\end{abstract}

Keywords: data record and storing, Arduino platform, wave gauge recording measurements, oceanographic platform in Katsiveli.

Acknowledgments: The work was carried out within the framework of state task No. 0827-20190004 "Complex interdisciplinary investigations of oceanologic processes conditioning functioning and evolution of the Black and Azov seas' coastal zone ecosystems". The authors are grateful to V. V. Malinovsky and V. A. Dulov for their discussions and valuable remarks on the work, and to E. B. Skiba - for his assistance in processing the initial data.

For citation: Smolov, V.E. and Rozvadovskiy, A.F., 2020. Application of the Arduino Platform for Recording Wind Waves. Physical Oceanography, [e-journal] 27(4), pp. 430-441. doi:10.22449/1573$160 X-2020-4-430-441$

DOI: $10.22449 / 1573-160 X-2020-4-430-441$

(C) V. E. Smolov, A. F. Rozvadovskiy, 2020

(C) Physical Oceanography, 2020

\section{Introduction}

Waves on the sea surface primarily affect floating vessels and various structures located in the coastal line. Data on wind waves and swell are necessary for many practical purposes (shipbuilding, hydrotechnical construction on the seas, navigation, fishing, calculation of hydrophysical, hydrochemical processes in the ocean, etc.) [1]. Such data is also necessary for wind waves theory development, improvement of methods for its modeling and forecast. Knowledge of the following main wave elements: the height of significant waves, their length and period, as well as the propagation direction and steepness, is necessary for the wave climate assessment $[2,3]$.

One of the most common measuring instruments for obtaining data on wind waves and swell is the wave gauge recorder. Ads per the installation site, wave recorders are distinguished as coastal, buoy and ship ones and as per the operation principle of operation - as string, acoustic, float with a rotator), etc.

The most widespread and simple-to-use are electrode wave gauge recorders with the primary measuring transducers being one or two electrodes immersed vertically in water. In accordance with measurement principle string (resistive) and 
capacitive wave gauge recorders are classified A description of the various designs of wave gauge recorders is given below.

The main attention in the development of wave gauge recorders is focused on their noise immunity increase, ensuring the measuring characteristic linearity of the device, reducing the resistive sensor (string) polarization. It occurs when using alternating (rectangular) voltage generators, leading to distortion of measurement results and mechanical destruction of the string (resistive sensor), etc.

At the same time, much less attention is paid to the issue of recording and storing the received data. This is partly due to the fact that when recording the wave gauge recorder data, an operator presence selecting the method of processing, recording and storing data and also controlling the recording process, is assumed.

Early wave gauge recorders used oscilloscopes *, a frequency counter $* *$ and other measuring instruments to record data.

In the patent $* * *$, in general terms, a microprocessor unit and a memory unit (flash memory), which register and record measurement results during one sounding session, are considered. The measurement results are read from the memory unit to the computer after the device is lifted to the surface, while the maximum duration of the measurement session is limited to 10 minutes.

In the patent $* * * *$, the immersion height of each string of the wave gauge recorder is recorded on the infrared photodetector matrix according to the interface position on the strings. Registration of the obtained results (images of strings) is made on a video camera, equipped with an infrared filter. This approach improves the measurement accuracy, but is associated with technical difficulties in implementation. Inparticular, it requires infrared light sources to illuminate the strings.

In the patent $* * * * *$, a matrix of photodetectors is used for registration. An additional source of illumination is also required.

Almost all of the solutions discussed above do not imply long-term autonomous operation.

Specialists of Marine Hydrophysical Institute of RAS developed and patented the string wave gauge recorder construction $* * * * * *$ [4]. Its advantages are high measurement accuracy, noise immunity and increased stable operation resource. This is achieved by converting the voltage of the signal measured from the resistive sensor into the frequency of the control signal and generating, depending on this frequency and a given signal (given sinusoidal oscillations applied to the resistive sensor).

* Vilenskiy, Ya.G. and Glukhovskiy, B.Kh., 1958. Ustroystvo dlya Distantsionnogo Izmereniya i Registratsii Elementov Morskikh Voln v Pribrezhnom Melkovodnom Rayone Morya [Instrument for Remote Measurement and Registration of Sea Wave Elements in the Coastal Shallow Sea Area]. Copyright Certificate 111740 USSR, 01.01 .58 ; Ibragimov, A.M., Agalarov, E.S. and Mamedyarov, Sh.D., 1961. Elektrokontaktnyy Volnograf [Electrocontact Wave Gauge Recorder]. Copyright Certificate 152071 USSR, 1961 ; Yakshin, A.N., 1965. Laboratornyy Volnograf [Laboratory Wave Gauge Recorder]. Copyright Certificate 176693 USSR, 17.11.65.

** Gopko, A.T., Golosko, V.A., Verkeev, P.P., Kolesov, S.O. and Tereshchenko, V.A., 1982. Volnograf [Wave Gauge Recorder]. Copyright Certificate 943526 USSR, 15.07.82.

*** Balakin, R.A. and Timets,V.M., 2013. Gidroakusticheskiy Avtonomnyy Volnograf [Hydroacoustic Autonomous Wave Gauge Recorder]. Patent Russia, no. 2484428, 10.06.13.

**** Sterlyadkin, V.V., Kulikovskiy, K.V. and Likhacheva, M.V., 2020. Strunnyy Volnograf s Infrakrasnoy Registratsiyey Dliny Strun [String Wave Gauge Recorder with Infrared String Length Recording]. Patent Russia, no. 2711585, 17.01.20.

***** Sterlyadkin, V.V., 2020. Opticheskiy Strunnyy Volnograf [Optical String Wave Gauge Recorder]. Patent Russia, no. 2712755, 31.01.20.

****** Smolov, V.E. and Rozvadovskiy, A.F., 2016. Strunnyy Volnograf [String Wave Gauge Recorder]. Patent Russia, no. 2016146 953, 29.05.18. 
Due to this wave gauge recorder operation specifics on the oceanographic platform in Katsiveli, the following tasks appeared in the development of its recording part, namely: autonomy of the operation; data recording continuity; stability of data recording and storage to external impacts (reducing the data loss risk); simplicity of implementation.

It should be noted that for the single- and six-string wave gauge recorders, it was necessary to develop two separate devices for wind waves recording, which is associated with different transmission rates and data volumes transmitted by each of them. A larger number of strings, a wider spectrum of operating frequencies of a six-string wave gauge recorder permit to determine not only the heights of the waves, but also their directions, which is necessary to assess the frequencyangular wave spectra. However, this requires greater computing capacity.

The present paper presents an example of the implementation of recording and storing data obtained from single- and six-string wave gauge recorders using the Arduino hardware and software platform and shows the circuit connection patterns circuit and block diagrams of programs. Greater processing capacities for the six-string wave gauge recorder were achieved using the more powerful Arduino Due board.

\section{Hardware}

The choice of the Arduino platform as the basis for the development of a device for recording and storing data on wind waves is due to the optimal combination of hardware and software characteristics [5]. This platform has its own development environment Arduino IDE; built-in free compiler from the $\mathrm{C} / \mathrm{C}++$ language (AVR GCC), which provides the creation as a result of binary file compilation of a user program with the HEX extension; free utility of the AVRDUDE programmer, which transfers the user program code in the form of a HEX file to the microcontroller bootloader on the Arduino board; a lot of free tools (AVR Studio, AVR GCC, AVR Libc and WinAVR) and libraries for them suitable for various operating systems (Windows, Linux and Mac). All this makes it possible to simplify and reduce the time required for the development and manufacture of the final product -a data recording and storage device.

Tasks in the process of the development of the recording part of the Arduinobased string wave gauge recorder were solved as follows:

- the recording continuity was ensured by asynchronous data transfer;

- noise immunity was provided due to the device autonomy (implementation in the form of a finished product), in which only the power supply line, protected by filters, is used from external connections;

- simplicity of implementation was achieved owing to the Arduino board use, which does not require special configuration tools for connecting external modules such as internal clock, time indicator and slot for SD memory cards.

The general block diagram of this device is shown in Fig.1 


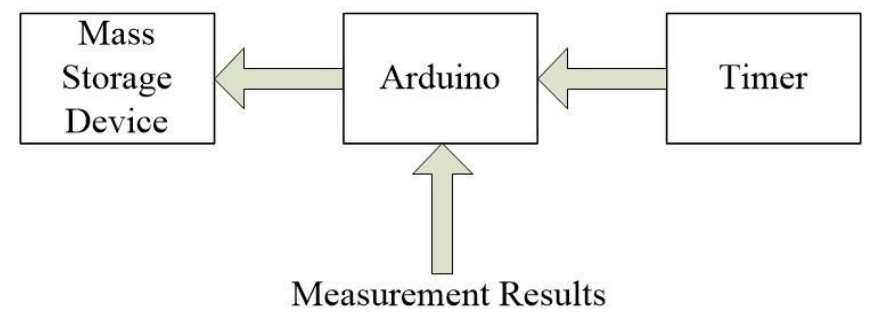

F i g. 1. Block diagram of data recording based on the Arduino platform

RS-232(Recommended Standard 232,URL:http://www.bitsavers.org/pdf/datapro/ communications_standards / 2741_EIA_RS-232-E.pdf) was selected as the interface for receiving data.

This interface is used to transfer measurement results in single- and six-string wave gauge recorders, which a device for recording and storing data was developed for. At the same time, it is hardware and software implemented for Arduino boards and does not require the use of additional interface devices and software.

SD-memory cards were chosen as storage devices. This choice is due to the fact that the wave gauge recorder is designed for year-round use in various (including heavy) meteorological conditions on the oceanographic platform in Katsiveli in isolation. In this case, it is not always possible to organize wired and/or wireless channels for data transmission. Therefore, it was decided to use the device for recording and storing data as an integral part of the wave gauge recorder in an autonomous mode. In this case, the data is recorded continuously and taken as the SD-cards are full.

The Arduino platform does not have its own built-in real-time clock, necessary to tie the obtained data to the time intervals the measurements were taken in. This is external modules are used for. The most common of them are modules made using the DS1302, DS1307 and DS3231 microcircuits.

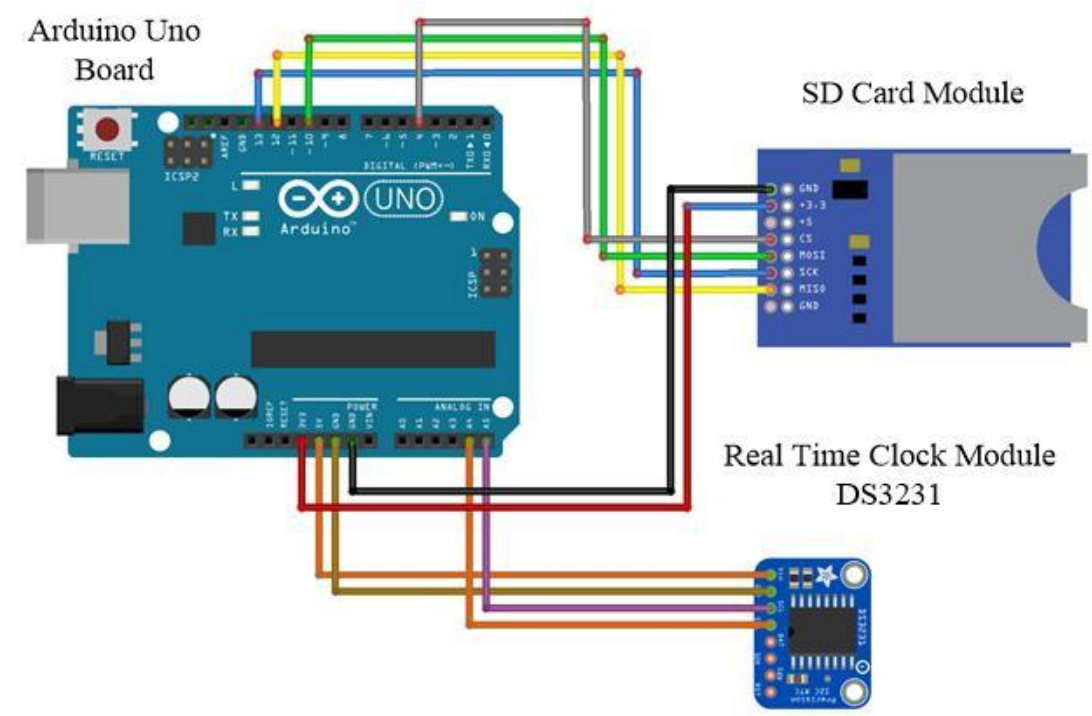

F i g. 2. Scheme of the recording part of a single-string wave gauge based on the Arduino Uno PHYSICAL OCEANOGRAPHY VOL. 27 ISS. 4 (2020) 
When developing an Arduino-based device for recording and storing data, various options for implementing a real-time clock were considered. As a result, the preference was given to the DS3231 microcircuit, since only it had built-in thermal stabilization, permitting to get increased accuracy compared to DS1302 and DS1307 (URL: https://datasheets.maximintegrated.com/en/ds/DS3231.pdf).

The block diagram of a single-string wave gauge recorder is shown in Fig. 2. Arduino Uno was used as the main board, which an eight-bit Atmel controller of the AVR family of the ATmega328 model with a clock frequency of $16 \mathrm{MHz}$ was used in (URL: http://ww1.microchip.com/downloads/en/DeviceDoc/Atmel-7810Automotive-Microcontrollers-ATmega328P_Datasheet.pdf). As mentioned earlier, an SD memory card was used as the data storage device. At the same time, to avoid data loss, it is recommended to use drives with a speed class not less than sixth (URL: https://www.sdcard.org/downloads/pls/latest_whitepapers/Application_ Peformance_Class_White_Paper.pdf).

In the six-string wave gauge recorder, in contrast to the single-string gauge wave recorder, the Arduino Due was used as the main board in the device for data record and storage (Fig. 3).

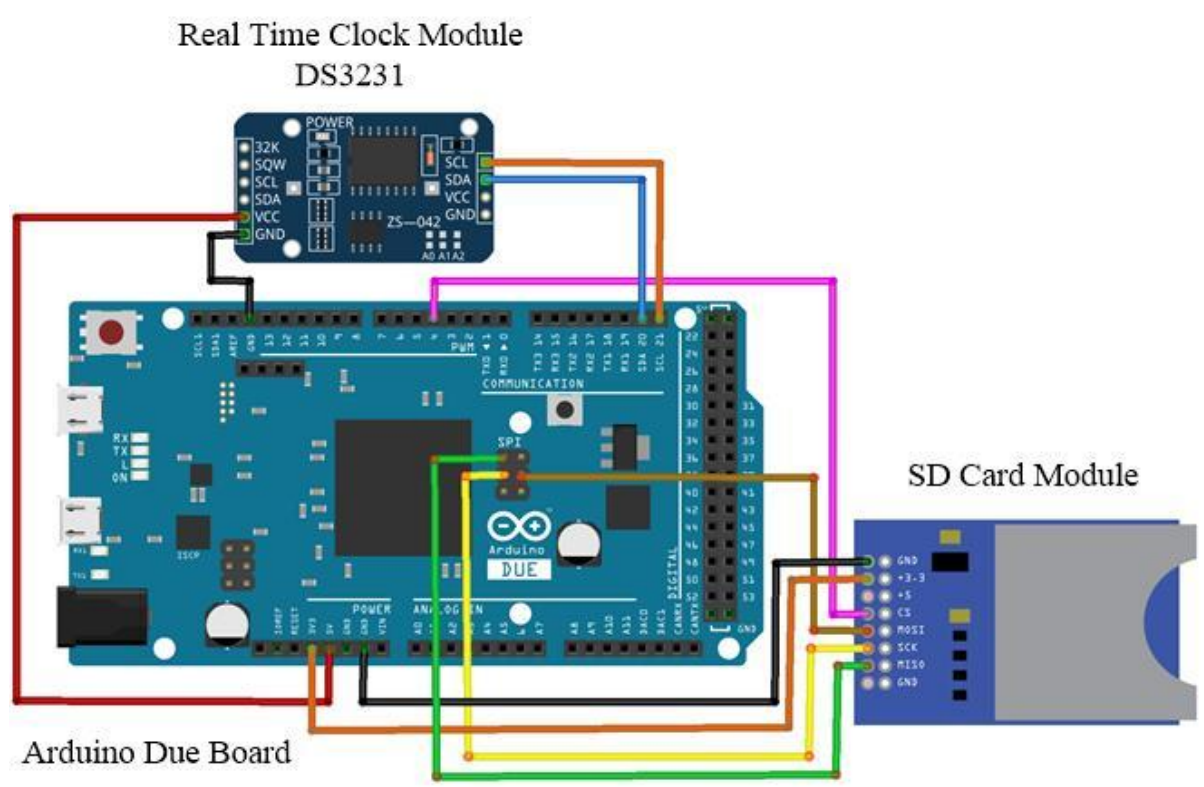

F i g. 3. Scheme of the recording part of a six-string wave gauge recorder based on the Arduino Due

This board uses an Atmel AT91SAM3X8E 32-bit microcontroller of the ARM family with a Cortex-M3 core, operating at $84 \mathrm{MHz}$ (URL: http://www.atmel.com/Images/Atmel-11057-32-bit-Cortex-M3- MicrocontrollerSAM3X-SAM3A_Datasheet.pdf), due to which greater productivity is achieved. 


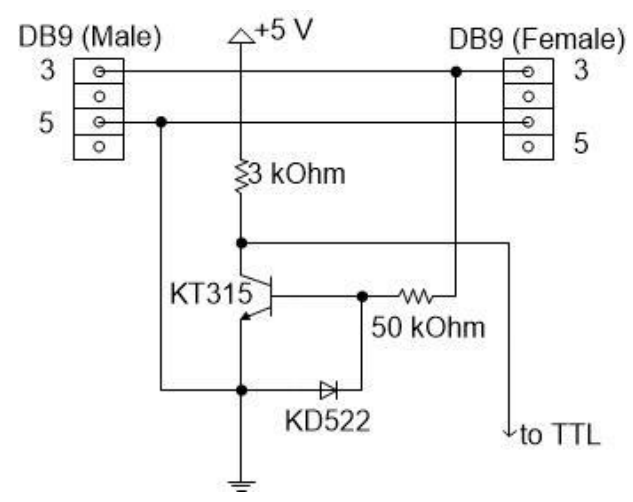

F i g. 4. Voltage converter scheme at the COM-port circuit input of the Arduino board

The built-in Arduino COM-port allows the direct connection of the devices to it via the RS-232 interface, the logical "0" of which corresponds to a positive voltage (from 5 to $15 \mathrm{~V}$ for the transmitter), and logical "1" corresponds to a negative voltage (from -5 to $-15 \mathrm{~B}$ for the transmitter). However, given that the operating voltages of microcontrollers on Arduino boards are voltages of 5 or $3.3 \mathrm{~V}$ (depending on the board model), to protect the input ports, voltage conversion (lowering) was applied using a converter (see its scheme in Fig. 4). Thus, the device for data record and storage is protected from possible overloads on the COM-port.

\section{Software}

When developing the software part, the attention was focused on two issues data reading from the COM-port and linking the results to time. The program algorithm is shown in Fig. 5 (blocks are outlined with solid lines).

This program automatically starts in an infinite loop after the voltage supply is applied to the Arduino board and is interrupted either after it is stopped or after the board restart.

When developing the program algorithm, special attention was paid to the data reading and writing continuity, and also with the aim of minimizing data loss in the event of a power failure of the device. For this, as mentioned earlier, the asynchronous mode of reading data from the COM-port was selected. This mode is slower than the parallel one, but the data is not stored in the Arduino board RAM (buffer), but almost immediately written to the memory card. Nevertheless, even in this case, there is a risk of losing information, namely a byte with data stored in the buffer of the COM-port of the Arduino board.

Of the two options for implementing the asynchronous mode of data reading byte and block reading - the second was chosen. This is due to the fact that reading one byte at a time for the available data rates $(9600 \mathrm{bps}$ for a single-string and $38,400 \mathrm{bps}$ for a six-string wave gauge recorder) leads to data loss as that the device does not have time to complete the program cycle of data recording and storage ( Fig. 5) until the next byte arrives. 


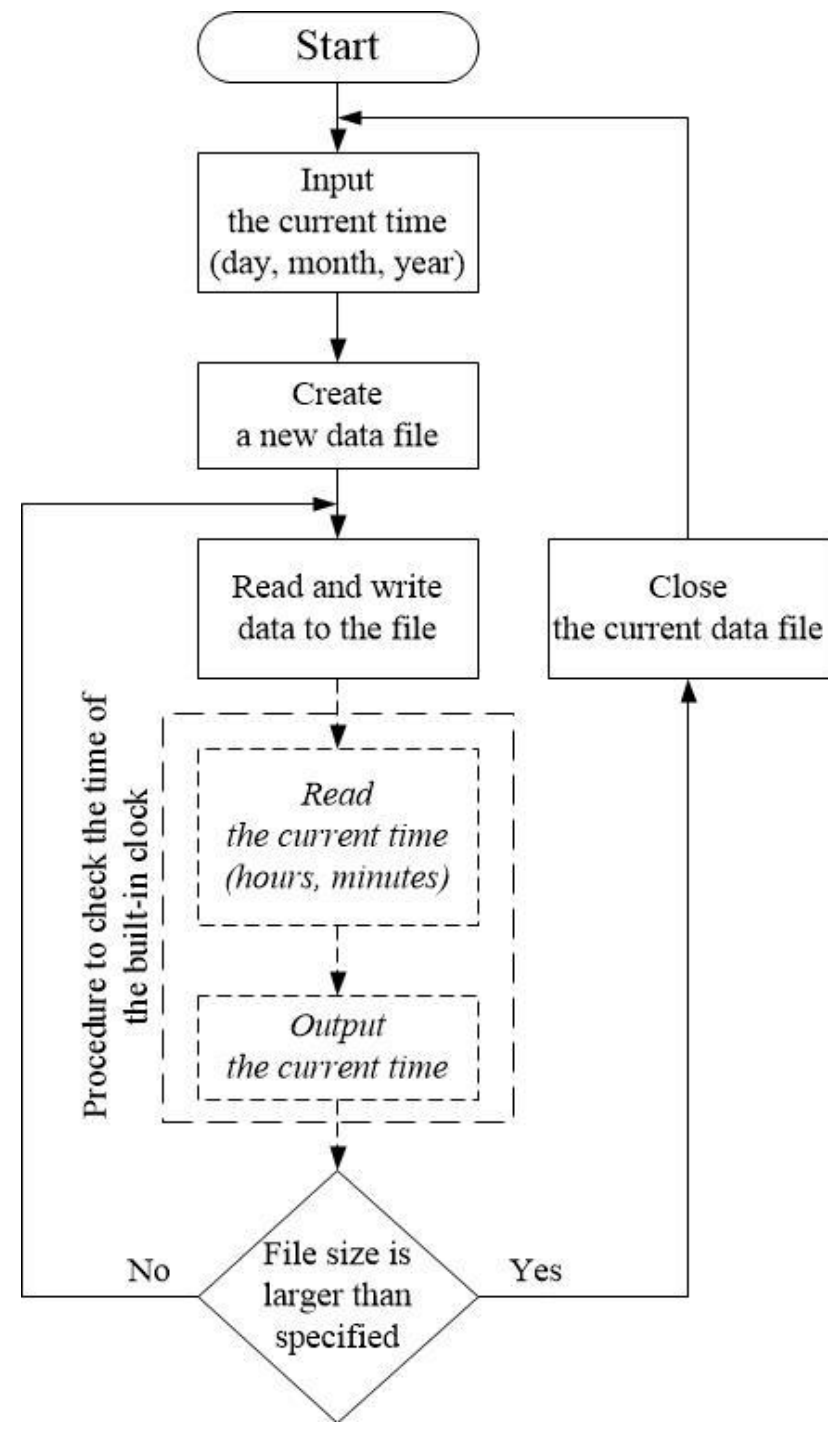

F i g. 5. Block diagram for data recording algorithm using the Arduino board

The block size was chosen as small as possible to reduce data loss due to device malfunctions: for a single-line wave gauge recorder - 100 bytes; for sixstring -800 bytes.

Another issue that had to be resolved in the development of a recording and storage device was the timing of the results obtained. Considering that the data from the wave gauge recorder goes in a continuous stream in the form of frames, inserting the current time into this stream would require tight synchronization of each frame at the COM-port input of the Arduino board and the DS3231 clock.

To simplify the circuit, it was decided to record the input data stream as fixedsize files. The current file name corresponds to the start time of the recording, the next file time corresponds to the end time of the recording of the previous one. 
Taking into account that the data recording rate is a constant value, and each frame within the file has its own number, using this data, it is possible to restore the chronology of events (recording information from the wave gauge recorder).

It is important to note that the Arduino platform has a limit on the length of the file name - no more than 8 characters. Therefore, the file name was set as follows:

\section{MMDDHHMM.wYY,}

where MM is the month; DD is the date; $\mathrm{HH}$ are hours; MM are minutes; wYY is the binary file extension where YY are year numbers.

The initial DS3231 clock setting is carried out once when the program is first started when setting up the recorder and storage device, after which this code fragment is commented out.

Lack of the current time indication leads to impossibility of the control of the internal time of the wave gauge recorder. As a result, any internal clock failure is fraught with the fact that the file name will indicate an inaccurate time and the received data will be difficult to link to their recording time. Therefore, a time indicator based on the TM1637 microcircuit was included in the recording device for continuous monitoring of the current time.

As a result, the program code underwent certain changes (see the block diagram in Fig. 5). A procedure for processing data - the current time - and displaying the result on the indicator (outlined by a dashed line) was added to it. To display the current time, a four-digit seven-segment indicator based on the TM1637 microcircuit was added to the wave gauge recorder (Fig. 6).

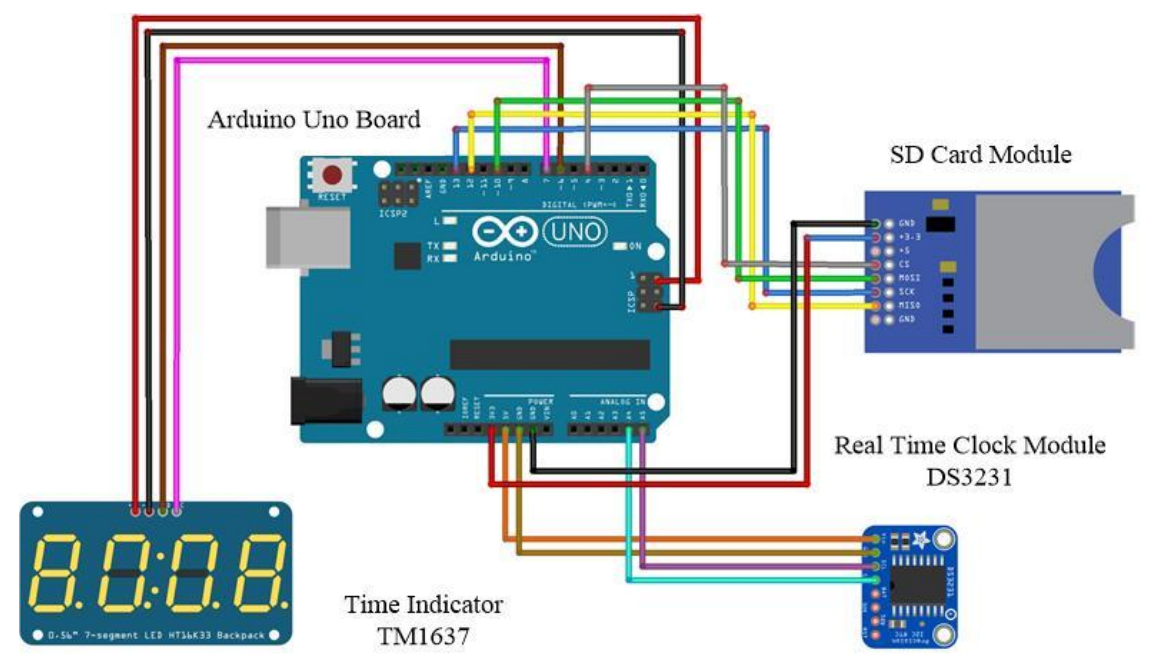

F i g. 6. Scheme of the recording part of a single-string wave gauge recorder based on the Arduino Uno board with indication of current time 
Time reading from the DS3231 microcircuit and output to the TM1637 indicator is carried out each cycle of data reading from the COM-port. This allows, in the event of a device failure or freeze, to determine the moment in time when an abnormal situation occurred, and to analyze its causes to exclude a recurrence in the future.

\section{Experience of use}

In a device for recording and storing data based on the Arduino platform, the main board of the Arduino Uno and the memory card, clock and indicator are located inside a dust and moisture protected case, which ensures their protection from environmental influences (Fig. 7).

Two DB9 connectors (male and female) are connected in parallel for the purpose of relaying data. In this case, it is not only stored in an external medium - an SD card (its connection slot is shown in Fig. 7, b), but can also be output to another external device (for example, the COM-port of a PC). The indicators show the power supply presence and the process of data transfer (registration).

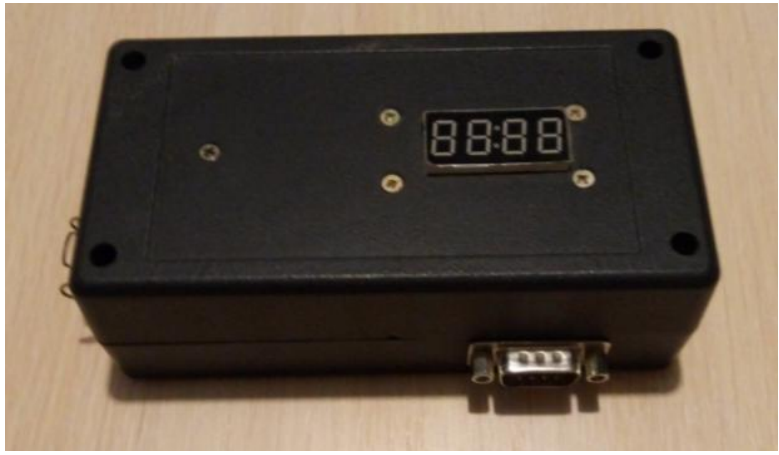

$a$

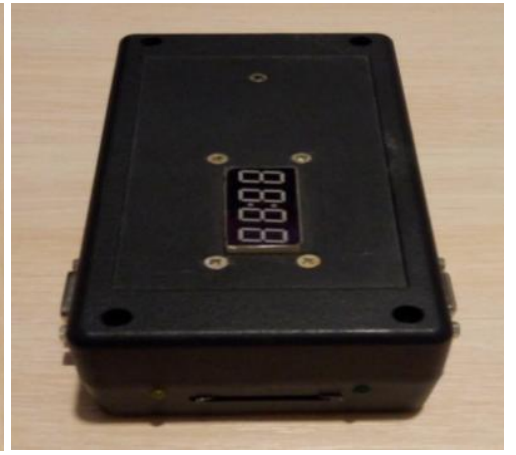

$b$

F i g. 7. Appearance of the device for data recording and storing for a single-string wave gauge recorder

The data logger for the single-string wave gauge recorder began to be used in test mode for recording data on the oceanographic platform in Katsiveli in May 2015. Since July 2016, it has already worked in a continuous year-round mode of data recording and storage. During this time, a data array of about 10 GB was obtained.

The first test runs of the recording device for the six-string wave gauge recorder were carried out in in June, 3-10 2019, test operation was carried out in September, 9-26, 2019. Operating experience has shown that the time desynchronization of the data recording and storage device lies within \pm 2 minutes per year and can be programmatically adjusted. The malfunctions that took place during this time, in $90 \%$ of cases, are due to power failures; no hardware or software failures were identified. 
Fig. 8 shows an example of registration of the main wave characteristic of the sea surface - the height of significant waves Hs during 2019. It was obtained using the discussed device for a single-string wave gauge recorder. The gap in data registration in October 2019 is associated with the implementation of work on the equipment modernization.

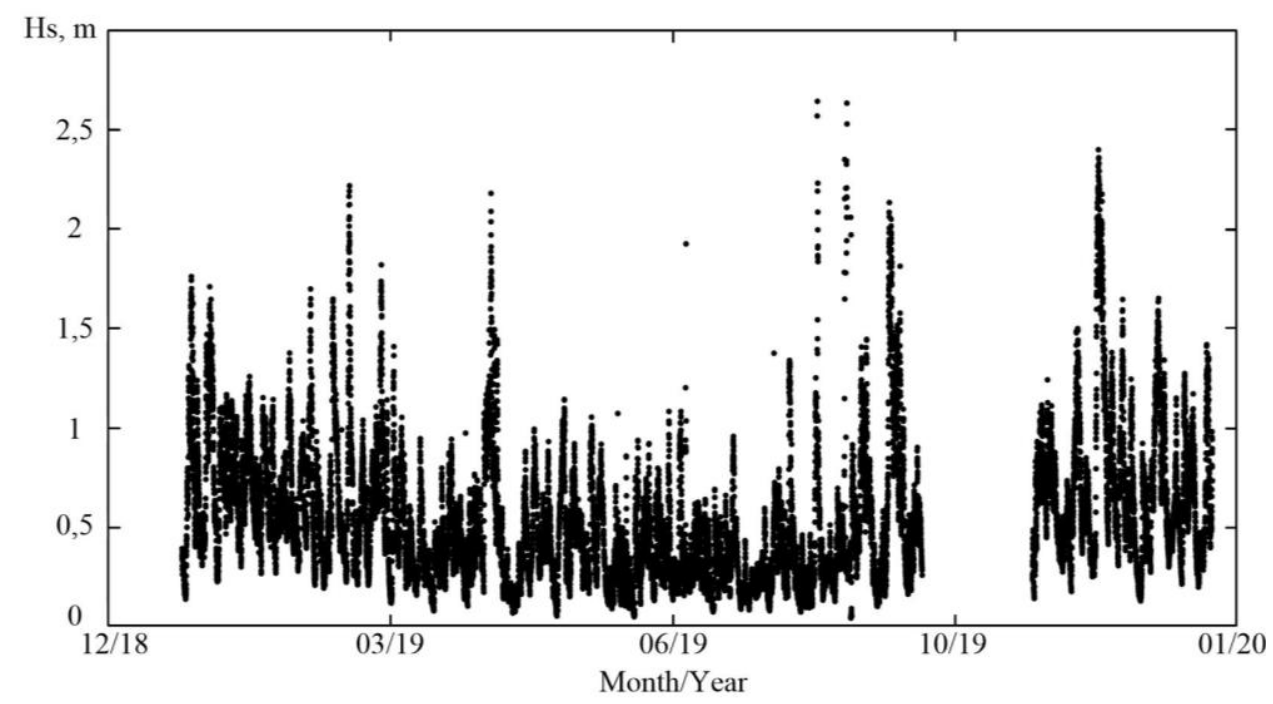

F i g. 8. Results of recording the significant wave heights $H s$ during 2019

The results obtained by means of this wave gauge recorder on the Arduino platform were used within the framework of the FTP project RFMEFI57714X0110 "Diagnostics" ("Development of methods and creation of an experimental model of a system for monitoring anthropogenic impacts on the shelf zones of the Black Sea coast of the Russian Federation, including Crimea, based on satellite and contact data") and when carrying out state orders of Marine Hydrophysical Institute of RAS, they were published in [6-10].

\section{Conclusion}

The variant of implementation of a device for recording and storing data obtained from a string wave gauge recorder on the Arduino hardware and software platform is described. The proposed solution ensures the continuity of data recording directly to an external storage medium (SD card), minimizing the risk of data loss in the event of a malfunction. At the same time, the device operates autonomously, is characterized by low power consumption and does not require the constant presence of technical specialists. Data is recorded to binary files, with no requirements to its content or format.

Time synchronization (binding of data to the moment of their recording) is provided in the file name, thus eliminating distortion of the measurement results 
when additional information is added by the data recording device (the Arduino board itself).

The Arduino platform flexibility, the ease of programming and connecting external expansion modules (external storage media, internal clocks, indicators, etc.) simplify the implementation and increase the reliability of the data recording and storage device as a whole, as evidenced by the experience of its operation on the oceanographic platform in Katsiveli.

\section{REFRENCES}

1. Goda, Y., 2000. Random Seas and Design of Maritime Structures. Singapore: World Scientific Publishing Co., 443 p.

2. Young, I.R., 1999. Wind Generated Ocean Waves. Amsterdam: Elsevier, 287 p.

3. Massel, S.R., 2013. Ocean Surface Waves: Their Physics and Prediction. Singapore: World Scientific Publishing Co., 800 p.

4. Shokurov, M.V., Dulov, V.A., Skiba, E.V. and Smolov, V.E., 2016. Wind Waves in the Coastal Zone of the Southern Crimea: Assessment of Simulation Quality Based on In Situ Measurements. Oceanology, 56(2), pp. 214-225. doi:10.1134/s0001437016020181

5. Yurovsky, Y.Y. and Dulov, V.A., 2017. Compact Low-cost Arduino-based Buoy for Sea Surface Wave Measurements. In: IEEE, 2017. 2017 Progress in Electromagnetics Research Symposium - Fall (PIERS - FALL). Singapore: IEEE, pp. 2315-2322. doi:10.1109/PIERSFALL.2017.8293523

6. Bondur, V.G., Ivanov, V.A., Dulov, V.A., Goryachkin, Yu.N., Zamshin, V.V., Kondratiev, S.I., Lee, M.E., Mukhanov, V.S., Sovga, E.E. and Chukharev, A.M., 2018. Structure and Origin of the Underwater Plume Near Sevastopol. Fundamentalnaya $i$ Prikladnaya Gidrofizika, 11(4), pp. 42-54. doi:10.7868/S2073667318040068 (in Russian).

7. Kornienko, A.I., Dulov, V.A., Malinovsky, V.V. and Kudryavtsev, V.N., 2019. Modulation of Breaking of Long Wind Waves. In: MHI, 2019. [Seas of Russia: Fundamental and Applied Research. Sevastopol, 23-28 September 2019: proceedings]. Sevastopol: MHI, pp. 350-351 (in Russian).

8. Panfilova, M., Ryabkova, M., Karaev, V. and Skiba, E., 2020. Retrieval of the Statistical Characteristics of Wind Waves from the Width and Shift of the Doppler Spectrum of the Backscattered Microwave Signal at Low Incidence Angles. IEEE Transactions on Geoscience and Remote Sensing, 58(3), pp. 2225-2231. doi:10.1109/TGRS.2019.2955546

9. Padokhin, A.M., Kurbatov, G.A., Nazarenko, M.O. and Smolov, V.E., 2018. GNSS Reflectometry of the Black Sea Level in the Experiments at the Stationary Oceanographic Platform. Moscow University Physics Bulletin, 73(4), pp. 422-427. doi:10.3103/S0027134918040112

10. Bondur, V.G., Ivanov, V.A., Vorobiev, V.E., Dulov, V.A., Dolotov, V.V., Zamshin, V.V., Kondratiev, S.I., Lee, M.E. and Malinovsky, V.V., 2020. Ground-to-Space Monitoring of Anthropogenic Impacts on the Coastal Zone of the Crimean Peninsula. Physical Oceanography, 27(1), pp. 95-107. doi:10.22449/1573-160X-2020-1-95-107

About the authors:

Vladimir E. Smolov, Leading Electronics Engineer, Marine Hydrophysical Institute of RAS (2 Kaptanskaya St., Sevastopol, Russian Federation, 299011), vladimir.smolov@ mail.ru

Andrey F. Rozvadovskiy, Junior Research Associate, Marine Hydrophysical Institute of RAS

(2 Kaptanskaya St., Sevastopol, Russian Federation, 299011), Ph. D. (Engin.), rozvadovsky@yandex.ru 
Contribution of the co-authors:

Vladimir E. Smolov - development of a block diagram, operation algorithms and program code for data recording of a wind wave gauge recording device based on the Arduino platform

Andrey F. Rozvadovskiy - development of a schematic diagram, manufacturing and testing of a wind wave gauge recording device based on the Arduino platform

All the authors have read and approved the final manuscript.

The authors declare that they have no conflict of interest. 